\title{
A Fault Analysis on AC Microgrid with Distributed Generations
}

\author{
Seong-Su Shin*, Joon-Seok Oh**, Su-Hyeong Jang ${ }^{\S}$, Woo-Kyu Chae ${ }^{\S \S}$, Jong-Ho Park** \\ and Jae-Eon Kim ${ }^{\dagger}$
}

\begin{abstract}
As the penetration of different types of renewable energy sources (RES) and energy storage systems (ESS) increases, the importance of stability in AC microgrid is being emphasized. Especially, RES and ESS which are operated using power electronics have difference in output characteristics according to control structures. When faults like single-line-to-ground fault or islanding operation occur, this means that a fault should be interpreted in different way. Therefore, it is necessary to analyze fault characteristics in $\mathrm{AC}$ microgrid in case of grid-connected mode and standalone mode. In this paper, the fault analysis for AC microgrid is carried out using PSCAD/ EMTDC and an overvoltage problem and the countermeasures were proposed.
\end{abstract}

Keywords: Microgrid, Distributed generation, Overvoltage, Distribution system, Islanding

\section{Introduction}

For some stakeholders to desire high-level of electric power quality, AC microgrid could be a solution that replaces the utility power supply. Especially, the owner of AC microgrid has various benefits depending on its operation functions. In general, those functions are considered as grid-connected operating mode and standalone operating mode. The grid-connected operating mode can implement demand response (DR) based on time-ofuse (TOU) to exchange power under system marginal price (SMP). The stand-alone operating mode can perform uninterrupted power supply (UPS) function to continue to supply electricity even in blackout event. Due to these advantages, the penetration of $\mathrm{AC}$ microgrid will be increased [1].

Meanwhile, the fault analysis for area electric power system (EPS) with AC microgrid should be considered in its design and planning for stakeholders and utility operators to fully utilize the previous benefits. For the fault analysis, the characteristic of $\mathrm{AC}$ microgrid sources must be also considered. The source of AC microgrid consists of different types of RES and ESS. RES and ESS which are operated using power electronics have difference in output characteristics by control structures. However, the conventional power systems and electrical protection devices were well designed for voltage-controlled sources

$\dagger$ Corresponding Author: School of Electriccal Engineering, Chungbuk National University, Korea. (jekim@cbnu.ac.kr)

* $\quad$ Electric Association, Korea. (shinss@elec.or.kr)

** School of Electrical Engineering, Chungbuk National Univ., Korea. (\{simeter, jongho6513\}@naver.com)

$\S \quad$ R\&D Lab. in LS Industrial Systems Co., Korea. (suhjang@1sis.com)

$\S \S \quad$ KEPCO Research Institute

(microgrid@kepco.co.kr)

Received: February 25, 2016; Accepted: June 30, 2016 like synchronous generators. On the contrary, most of AC microgrid sources are based on inverter-based source [2]. It means that inverter-based sources like RES and ESS are not voltage-controlled sources in grid-connected operation and might bring serious impacts on area EPS and AC microgrid when fault occurs [3].

In grid-connected operation, all distributed generation (DG) should be controlled using grid-feeding control. The purpose of grid-feeding control is to generate a desired value of active and reactive power. It has no capability to generate a constant voltage and constant frequency. On the other hand, at least one DG should be controlled using grid-forming control in standalone operation. Hence, the fault analysis should be considered by different ways based on the difference of control structures between the two operations [4]. Especially, the voltage problem can happen in $\mathrm{AC}$ microgrid considering most of DGs are operating grid-feeding control.

In this paper, various cases of fault in $\mathrm{AC}$ microgrid are analyzed and considered. In addition, the proper countermeasures are also proposed in this paper. Section 2 introduces control structures of AC microgrid which consists of grid-feeding and grid-forming converter. Section 3 briefly describes fault types in AC microgrid like single-line-to-ground (SLG) and unintentional islanded operation and gives an explanation of overvoltage in $\mathrm{AC}$ microgrid during faulty. The simulations of these cases are included in Section 4 considering grid-connected operation. The type of fault is composed of and unintentional islanding operation in which DG energizes AC microgrid under SLG but when area EPS detects the fault and is disconnected. And the proper countermeasures of overvoltage are introduced in Section 5 as well. These procedures are carried out through PSCAD/EMTDC software package. 


\section{Control Structures of AC Microgrid}

AC microgrid has usually two operating functions which are composed of grid-connected operating mode and standalone operating mode. Fig. 1 shows the configuration of AC microgrid. In grid-connected operation static transfer switch (STS) is closed and all DGs should be controlled using grid-feeding control. In addition, distributed energy storage (DES) should be also operated as grid-feeding control. On the other hand, DES should constantly generate a voltage and frequency in standalone operation with open of STS [5]. Grid-connected operation is complemented by grid-feeding converters and the last by grid-forming converters. Generators in AC microgrid can be classified into two control structures, grid-feeding and grid-forming

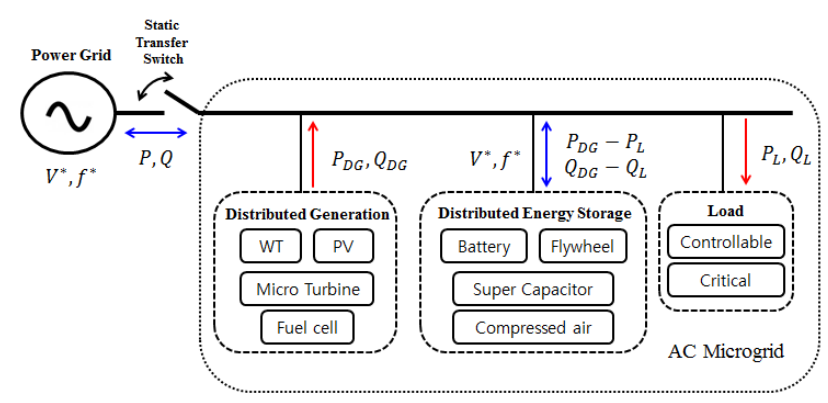

Fig. 1. The configurations of $\mathrm{AC}$ microgrid

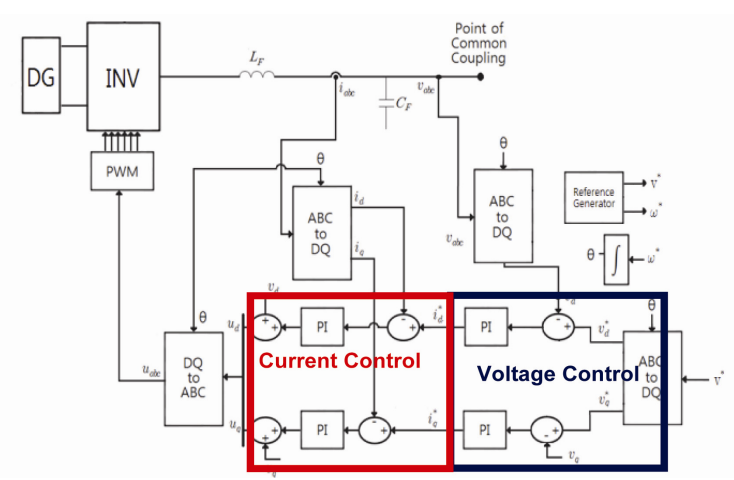

(a) Grid-forming control of DG in AC Microgrid

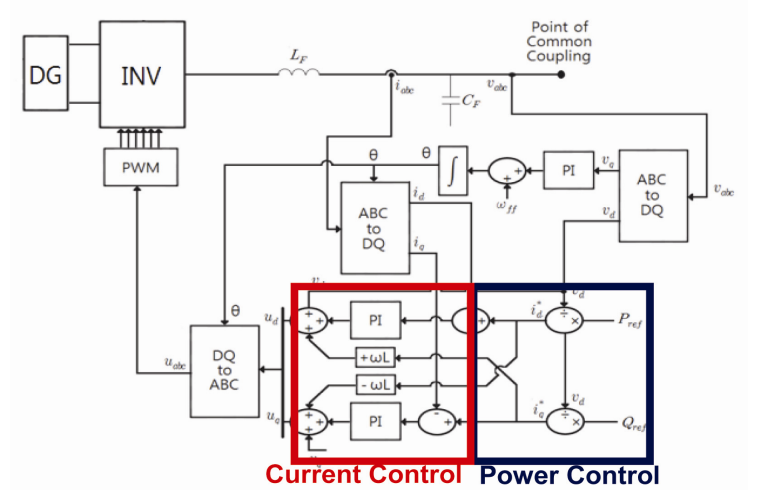

(b) Grid-feeding control of DG in AC Microgrid

Fig. 2. The control structures of distributed generation converters, to perform the perfect operation of $\mathrm{AC}$ microgrid.

Grid-forming converter can be represented as ideal voltage sources. The role of grid-forming converter is keeping a constant voltage $V^{*}$ and a constant frequency $\omega^{*}$, namely constant voltage constant frequency (CVCF) like as area EPS in order to supply to customers the electricity within permissible ranges. The control structure of grid-forming converter is following as Fig. 2(a). On the other hand, the role of grid-feeding converter is producing or absorbing real and reactive powers to $\mathrm{AC}$ microgrid or area EPS. Therefore, it is generally designed as currentcontrolled sources. Furthermore, phase lock loop at the PCC should be completely implemented for accurate control of active power $P^{*}$ and reactive power $Q^{*}$. The control structure of grid-feeding converter is following as Fig. 2(b) [4]. AC microgrid needs grid-forming converter at least more than one for its stand-alone operating to maintain its voltage and frequency properly. Also, the gridforming converter should be convertible between gridforming and grid-feeding mode in case of grid-connected mode because the constant voltage and frequency is already controlled by power grid.

\section{Overvoltage Problems of AC Microgrid during Islanding Operation}

Microgrid operators should consider the various situations in grid-connected operation and standalone operation. For example, the power grid can be separated from the AC microgrid due to the protection from SLG. In this situation, all DGs are operating using grid-feeding control. However, these cannot form a CVCF source based on the control structures of grid-feeding control. It implies that power quality problems caused by unstable voltage should be considered during islanding operation [6]. Fig. 3 shows the fault case of islanding operation after detecting SLG in grid-connected operation. For quick protection of $\mathrm{AC}$ microgrid, protective devices like circuit breaker should separate grid from AC microgrid using main or backup protection in Fig. 3 and it should be performed within few seconds according to the many standards. The overcurrent in fault point can be dealt with by conventional countermeasures. However, the overvoltage can happen after islanding operation by separating from grid. The voltage during islanding operation is determined by load characteristic and control structures of DG. Until now, a method to decide the voltage during islanding is proposed as like Eq. (1) $[6,8]$ :

$$
V_{\text {islanding }(p . u .)}=\frac{\text { Total amount of power generation }}{\text { Total amount of load demand }}
$$

However, Eq. (1) does not give to identify a clear 


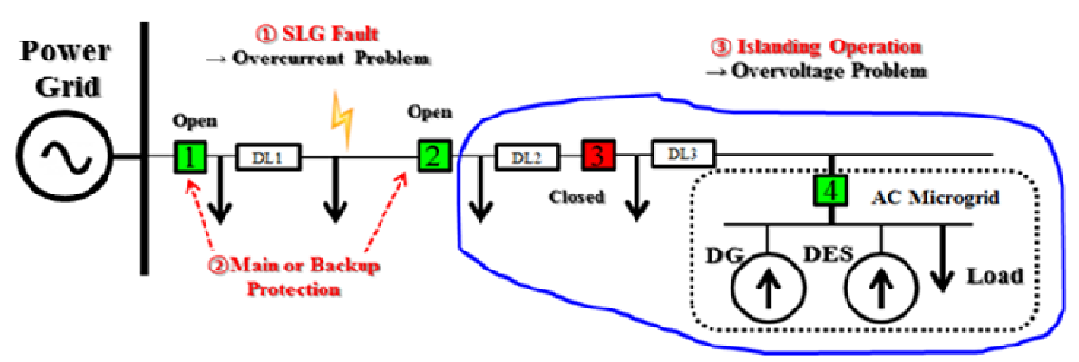

Fig. 3. A general fault case of AC microgrid in grid-connected operation

relationship between load and DG output. In addition, Eq. (1) should be considered a variety of load characteristic $s$ such as constant impedance, constant current and constant power [7]. Let assume that the power flow condition under grid-connected operation is as follows:

$$
\sqrt{P_{S}^{2}+Q_{S}^{2}}=\sqrt{\left(P_{L}-P_{D G}\right)^{2}+\left(Q_{L}-Q_{D G}\right)^{2}}
$$

where,

$P_{L}, Q_{L} \quad$ : active and reactive power of load

$P_{D G}, Q_{D G}$ : active and reactive output power of DG

$P_{S}, Q_{S} \quad$ : active and reactive power from power grid

Let see the constant impedance load expressed as follows:

$$
\sqrt{P_{L}^{2}+Q_{L}^{2}}=\sqrt{P_{0}^{2}+Q_{0}^{2}}\left(\frac{V_{L}}{V_{0}}\right)^{2}
$$

where,

$$
\begin{array}{ll}
P_{0}, Q_{0} & : \text { active and reactive power at rated voltage } \\
V_{0} & : \text { rated voltage } \\
V_{L} & : \text { voltage magnitude at } P_{L}+j Q_{L}
\end{array}
$$

From this situation, if islanding occurs, $P_{S}$ and $Q_{S}$ become to be zero and then $P_{L}=P_{D G}, Q_{L}=Q_{D G}$ respectively. Hence, the power flow condition under islanding can be written as follows:

$$
\sqrt{P_{D G}^{2}+Q_{D G}^{2}}=\sqrt{P_{L}^{2}+Q_{L}^{2}}\left(\frac{V_{i s}}{V_{L}}\right)^{2}
$$

where $V_{i s}$ is voltage magnitude during islanding. Consequently, the voltage magnitude can be decided by Eq. (5).

$$
V_{i s}=V_{L} \frac{\sqrt{\sqrt{P_{D G}^{2}+Q_{D G}^{2}}}}{\sqrt{\sqrt{P_{L}^{2}+Q_{L}^{2}}}}
$$

Fig. 4 shows the voltage determination of islanded section with DG operated as grid-feeding converter. The

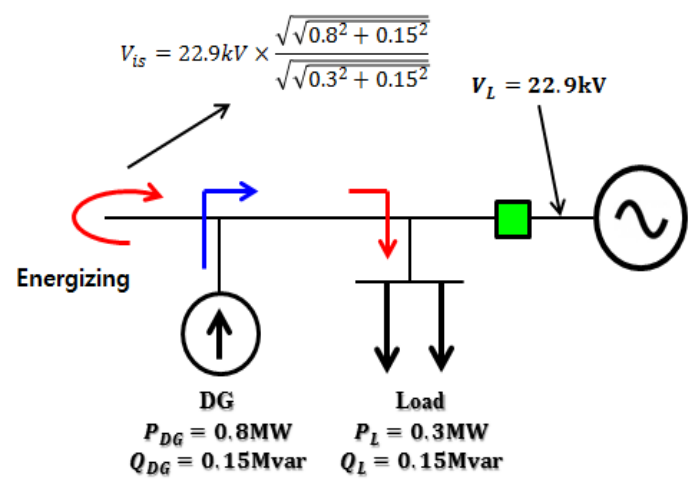

Fig. 4. Voltage determination of islanded section

Table 1. Standards of anti-islanding requirements

\begin{tabular}{c|c|l}
\hline Name & $\begin{array}{c}\text { Detection } \\
\text { Method }\end{array}$ & \multicolumn{1}{c}{ Requirements } \\
\hline $\begin{array}{c}\text { IEEE 1547 } \\
\text { IEC 61727 [11],[12] }\end{array}$ & $\begin{array}{c}\text { Active or } \\
\text { Passive }\end{array}$ & $\begin{array}{l}\text { Cease to energize within 2 seconds of } \\
\text { the formation of the island }\end{array}$ \\
\hline VDE-AR-N 4105 & $\begin{array}{c}\text { Active or } \\
\text { Passive }\end{array}$ & $\begin{array}{l}\text { Disconnect in } 5 \\
\text { seconds }\end{array}$ \\
\hline [13] & $\begin{array}{c}\text { Not } \\
\text { specified }\end{array}$ & $\begin{array}{l}\text { Network operator may have special } \\
\text { requirements }\end{array}$ \\
\hline JEAC 2008 $9701-2012$ & Passive & Detect within 0.5 sec \\
\cline { 2 - 3 }$[15]$ & Active & Detect within 0.5 1.0 sec \\
\hline KEPCO Guideline & $\begin{array}{c}\text { Active } \\
\text { or Passive }\end{array}$ & $\begin{array}{l}\text { Cease to energize within 0.5 seconds } \\
\text { of the formation of the island }\end{array}$ \\
\hline
\end{tabular}

section currently loses the ability of CVCF due to separation from the grid. Despite the absence of constant voltage, DG continuously tries to generate a constant power by decreasing output current while increasing voltage. However, active and reactive power might be inaccurately controlled based on the distortion of control signal. Moreover, this voltage is even more difficult to predict because reactive power imbalance in the islanded section might result in higher or lower the overvoltage depending on whether the load is inductive or capacitive and constant power or constant impedance model [8].

For these reasons, various methods of anti-islanding protection have been studied continually [9] and many standards for islanding operation have been established in many countries [10]. Table 1 shows the anti-islanding requirements of various standards. A lot of studies and standards propose the software solutions like fast measurement for quick tripping and restriction of DG penetration 
level as alternative. Nevertheless, the overvoltage can happen in few seconds faster than requirements and it is necessary to prevent an overvoltage.

\section{Simulation and Analysis}

In this paper, we analyze the fault characteristics in AC microgrid which composed of two grid-feeding converters and microgrid loads of constant impedance model. The SLG fault and unintentional islanding operation will happen during grid-connected mode of AC microgrid. To analyze the influence of fault on AC microgrid, an AC microgrid connected into $22.9 \mathrm{kV}$ distribution line through $154 \mathrm{kV} / 22.9 \mathrm{kV}$ substation transformer is considered as Fig. 5. All of the data for $154 \mathrm{kV} / 22.9 \mathrm{kV}$ substation, its transformer, load, $22.9 \mathrm{kV}$ distribution line and DGs in AC microgrid are as Table 2. The whole system is designed using PSCAD/EMTDC and all voltages and currents are measured in RMS value.

Fig. 6 shows the scenario of simulation in gridconnected operation. AC microgrid is normally operating

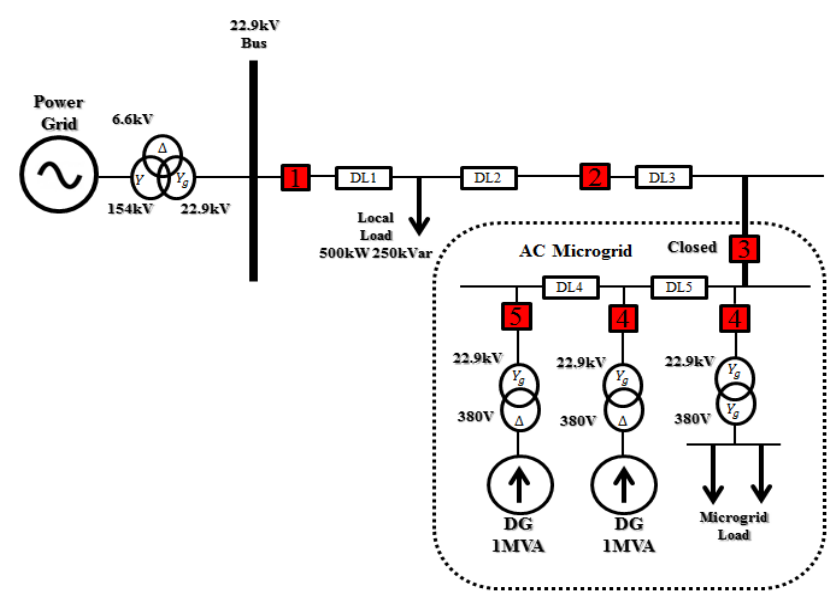

Fig. 5. The system configuration of AC Microgrid

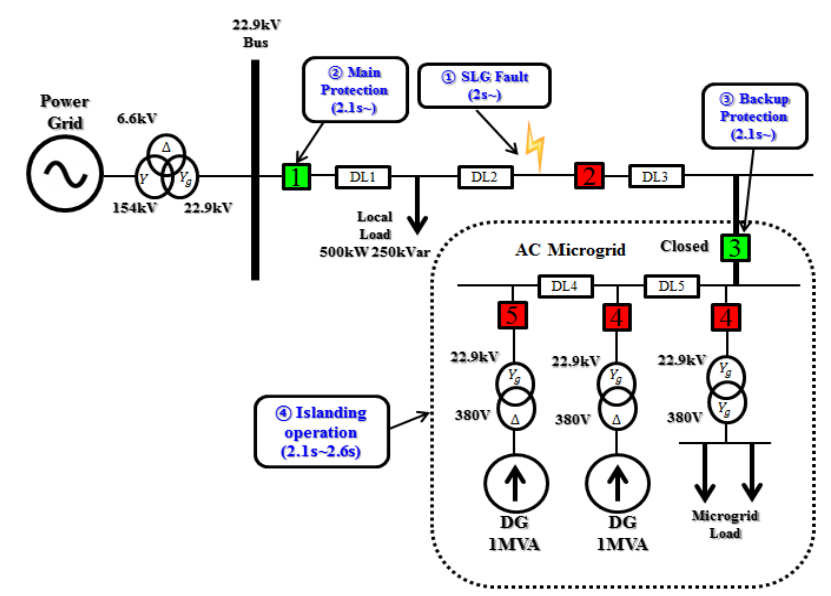

Fig. 6. The scenario of simulation in grid-connected operation as grid-connected mode for 2 seconds. After that, A-phase SLG fault occurs at 2 seconds and lasts until end of the simulation. In order to protect a power system from SLG fault, main protection and backup protection are performed at 2.1 seconds respectively. At the moment of main protection, islanding operation occurs due to separation from power grid. In addition, the anti-islanding requirement in KEPCO Guideline [16] is adopted in this simulation based on the fast cessation. Therefore, all of the DGs are stopped no later than 2.6 seconds. For grid-feeding converter, three cases of load demand in AC microgrid are considered as

Table 2. The specification of AC microgrid structure

\begin{tabular}{|c|c|c|}
\hline Index & Value & Remark \\
\hline \multicolumn{3}{|c|}{$154 \mathrm{kV}$ Grid Source } \\
\hline Positive Sequence \%Z & $0.08+\mathrm{j} 0.99$ & \multirow{2}{*}{$\begin{array}{c}\text { 100MVA } \\
\text { Based }\end{array}$} \\
\hline Zero Sequence $\% Z$ & $0.34+\mathrm{j} 1.69$ & \\
\hline \multicolumn{3}{|c|}{ 3-Winding Transformer(154kV-22.9kV-6.6kV) } \\
\hline Rated Power & 45/60MVA & \\
\hline Positive Sequence $\% X_{1-2}$ & j16.16 & \multirow{3}{*}{$\begin{array}{l}\text { 45MVA } \\
\text { Based }\end{array}$} \\
\hline Positive Sequence $\% X_{2-3}$ & j6.69 & \\
\hline Positive Sequence $\% X_{3-1}$ & $\mathrm{j} 25.38$ & \\
\hline Connection Type & $Y-Y_{g}-\Delta$ & \\
\hline \multicolumn{3}{|c|}{ Distribution Line $1\left(0.5 \mathrm{~km}, \mathrm{CVCN}-\mathrm{W} 325 \mathrm{~mm}^{2}\right)$} \\
\hline Positive Sequence \%Z & $0.72+\mathrm{j} 1.87$ & \multirow{2}{*}{$\begin{array}{c}\text { 100MVA } \\
\text { Based }\end{array}$} \\
\hline Zero Sequence \% $\mathrm{Z}$ & $2.23+\mathrm{j} 0.78$ & \\
\hline \multicolumn{3}{|c|}{ Distribution Line 2(1.5km, ACSR 160/95 mn') } \\
\hline Positive Sequence $\% \mathrm{Z}$ & $5.23+\mathrm{j} 11.62$ & \multirow{2}{*}{$\begin{array}{c}\text { 100MVA } \\
\text { Based }\end{array}$} \\
\hline Zero Sequence $\% \mathrm{Z}$ & $13.65+\mathrm{j} 34.2$ & \\
\hline Local Load & $\begin{array}{l}500 \mathrm{~kW}+ \\
250 \mathrm{kVar}\end{array}$ & Lagging \\
\hline \multicolumn{3}{|c|}{ Distribution Line $3\left(13.5 \mathrm{~km}\right.$, ACSR $\left.160 / 95 \mathrm{~mm}^{2}\right)$} \\
\hline Positive Sequence \%Z & $\begin{array}{r}47.25 \\
+\mathrm{j} 104.62 \\
\end{array}$ & \multirow{2}{*}{$\begin{array}{c}\text { 100MVA } \\
\text { Based }\end{array}$} \\
\hline Zero Sequence $\% \mathrm{Z}$ & $\begin{array}{r}122.85 \\
+\mathrm{j} 308.35 \\
\end{array}$ & \\
\hline \multicolumn{3}{|c|}{ Distribution Line 4,5(0.1 km, CVCN-W $\left.60 \mathrm{~mm}^{2}\right)$} \\
\hline Positive Sequence \% $\mathrm{Z}$ & $0.73+\mathrm{j} 0.31$ & \multirow{2}{*}{$\begin{array}{c}\text { 100MVA } \\
\text { Based }\end{array}$} \\
\hline Zero Sequence \% $\mathrm{Z}$ & $2.16+\mathrm{j} 6.77$ & \\
\hline \multicolumn{3}{|c|}{ AC Microgrid $\left(380 V_{L-L}\right)$} \\
\hline Type of DG & ESS & $2 \mathrm{EA}$ \\
\hline Rated Power & 1MVA & \\
\hline Transformer Connection & $Y_{g}-\Delta$ & \\
\hline Positive Sequence $\% \mathrm{X}(\mathrm{TR}+\mathrm{DG})$ & j0.05 & 1MVA Based \\
\hline
\end{tabular}

Table 3. Simulation condition for fault analysis in gridconnected operation

\begin{tabular}{|c|c|c|c|c|c|}
\hline Time & 0s & $2 \mathrm{~s}$ & $2.1 \mathrm{~s}$ & $2.6 \mathrm{~s}$ & $3 \mathrm{~s}$ \\
\hline \multicolumn{6}{|l|}{ SLG Fault } \\
\hline \multicolumn{6}{|l|}{$\begin{array}{l}\text { Islanding } \\
\text { Operation }\end{array}$} \\
\hline Action & - & $\begin{array}{l}\text { Fault } \\
\text { occurs }\end{array}$ & $\begin{array}{c}\text { CB1,CB2 } \\
\text { Open }\end{array}$ & $\begin{array}{l}\text { DGs } \\
\text { Halt }\end{array}$ & - \\
\hline Output of DGs & \multicolumn{5}{|c|}{ DG1 $=500 \mathrm{~kW}, 0 \mathrm{kVar}, \mathrm{DG} 2=300 \mathrm{~kW}, 150 \mathrm{kVar}$} \\
\hline $\begin{array}{l}\text { Microgrid } \\
\text { Load }\end{array}$ & \multicolumn{5}{|c|}{$\begin{array}{c}3 \text { cases : }(300 \mathrm{~kW}, 150 \mathrm{kVar}),(200 \mathrm{~kW}, 100 \mathrm{kVar}), \\
(100 \mathrm{~kW}, 50 \mathrm{kVar})\end{array}$} \\
\hline
\end{tabular}




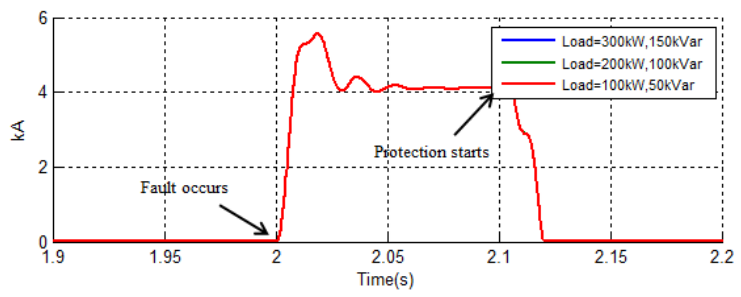

(a) A-phase current from grid-side

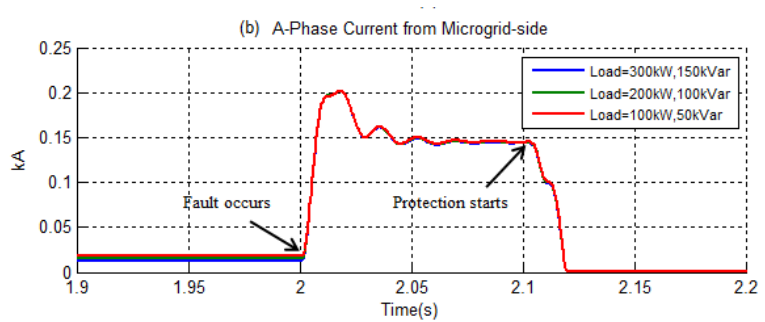

(b) A-phase current from microgrid-side

Fig. 7. A-phase current: (a) grid-side; (b) microgrid-side

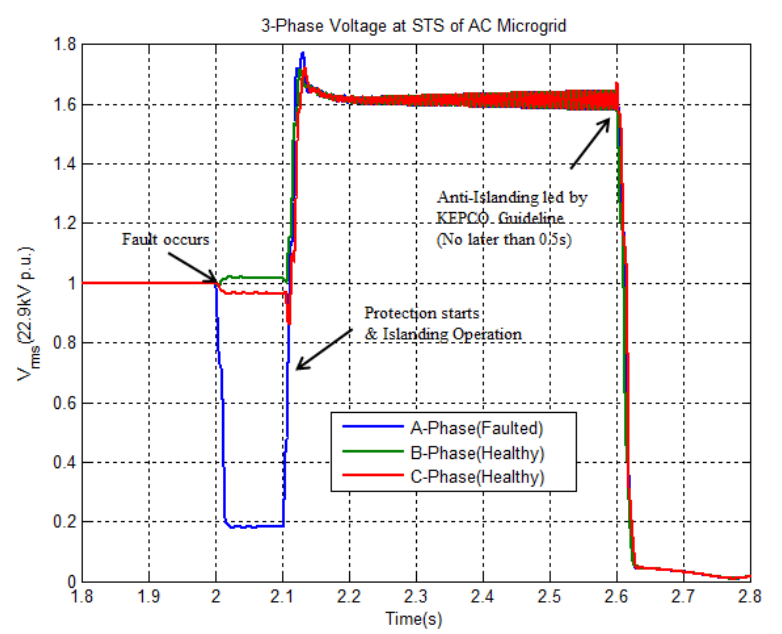

Fig. 8. 3-phase voltage at STS of AC microgrid (Load : $300 \mathrm{~kW}, 150 \mathrm{kVar})$

$300 \mathrm{~kW}$ and $150 \mathrm{kVar}, 200 \mathrm{~kW}$ and $100 \mathrm{kVar}, 100 \mathrm{~kW}$ and $50 \mathrm{kVar}$ respectively, and its limiting output is set to $110 \%$ of rated output power. And the fault resistance is zero in all of the simulation. The simulation condition is as Table 3 .

Fig. 7 shows the A-phase current from grid-side and microgrid-side. In general, most of unsymmetrical fault currents depend on the bus impedances and prefault voltage [17]. Therefore, the fault current is nearly equal to all cases in simulation. Regardless of load demand, the subtransient currents from grid-side and microgrid-side are $5.55 \mathrm{kA}$ and $0.202 \mathrm{kA}$ respectively. This result implies that it is appropriate to adopt the conventional overcurrent countermeasures such as setting the capacity of circuit breaker within $12.5 \mathrm{kA}$ of $520 \mathrm{MVA}$ in $22.9 \mathrm{kV}$ power system in Korea [18]. On the other hand, Fig. 8 shows the 3 -phase voltage at STS of AC microgrid in case of $300 \mathrm{~kW}$ and 150kVar load demand. During SLG, the voltage of faulted line is decreased and like conventional cases of fault. However, 3-phase voltages are dramatically increased to 1.61 p.u. after main and backup protection of power system. This value exceeds beyond the permissible range of voltage $1 \pm 0.05$ p.u and there is a concern on the overvoltage problem.

The phenomenon like Fig. 8 can be worsened depending on the load demand and power generation according to the Eq. (5). Fig. 9 shows the average RMS voltage at STS of AC microgrid with three cases of load demand. The maximum overvoltage values are 1.61 p.u., 1.97 p.u. and 2.79 p.u. respectively. Moreover, all cases exceed the upper limit of permissible voltage 1.05 p.u in $10 \mathrm{~ms}$. This result demonstrates that the change of voltage during islanding operation is influenced by the difference between power generation and load demand and fast blocking of voltage rise is necessary. Figs. 10 and 11 show the active and reactive power from DG1 and DG2 in AC microgrid. During SLG fault, DGs generates unstably because of unsymmetrical changes of control signal in control system.

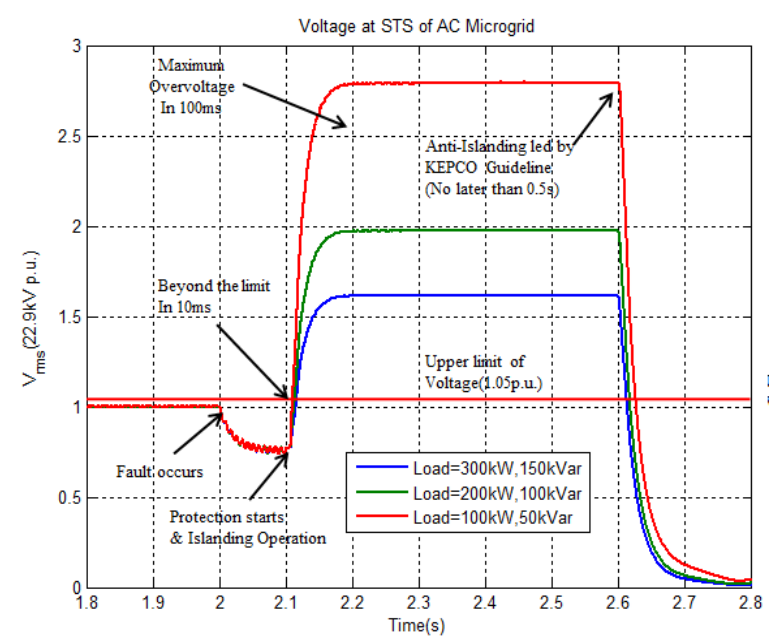

Fig. 9. The average RMS voltage at STS of AC microgrid
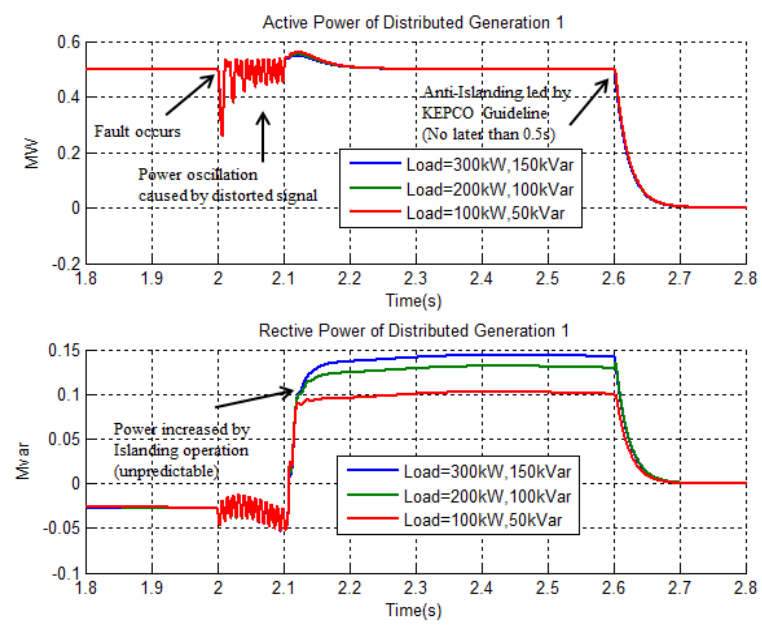

Fig. 10. Active and reactive power of DG 1 

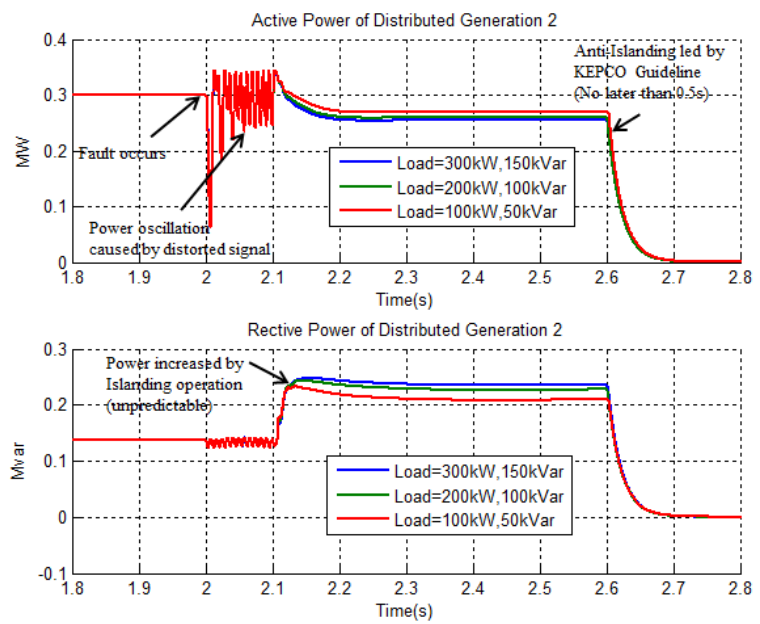

Fig. 11. Active and reactive power of DG 2

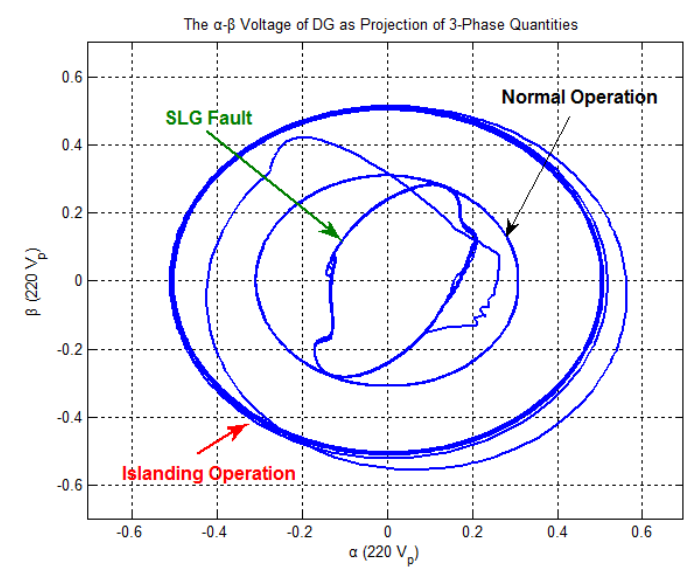

Fig. 12. The $\alpha-\beta$ voltage of $\mathrm{AC} \operatorname{microgrid}\left(380 \quad V_{L-L}\right)$ (Load : 300kW, 150kVar)

The power-electronic based DGs are commonly using abc- $\alpha \beta 0-\mathrm{dq} 0$ transformation because it can be employed to simplify the analysis of three-phase circuits [19]. For example, the $\alpha \beta$ signal of voltage can be oscillated or distorted like Fig. 12 by unsymmetrical fault. This distortion is the reason of unstable power generation of DG. In addition, the $\alpha \beta$ signal can be increased by islanding operation such as Fig. 12. It implies that input section of power and current control can be distorted and the change of power after islanding operation is not predictable. Table 4 shows the simulation results of overvoltage in case of $300 \mathrm{~kW}$ and $150 \mathrm{kVar}$ load demand. By Eq. (4), the voltage at islanded section can be calculated using power generation and load demand.

It should be considered in different ways in case of overvoltage during islanding operation. First, the gridfeeding control has no voltage control unlike grid-forming control. Second, the surplus power in AC microgrid can energize the area EPS if power generation is larger than load demand. Therefore, the capability of absorbing power generated by DGs or autonomous adjustment of power
Table 4. Simulation results of overvoltage (Load : 300kW, 150kVar)

\begin{tabular}{|c|c|c|c|c|}
\hline Index & \multicolumn{2}{|c|}{ Before islanding operation } & \multicolumn{2}{|c|}{ After islanding operation } \\
\hline & DG1 & DG2 & DG1 & DG2 \\
\hline$P_{D G}, Q_{D G}$ & $\begin{array}{l}0.5 \mathrm{MW} \\
0 \mathrm{Mvar}\end{array}$ & $\begin{array}{c}0.3 \mathrm{MW} \\
0.15 \mathrm{Mvar}\end{array}$ & $\begin{array}{c}0.5 \mathrm{MW} \\
0.13 \mathrm{Mvar}\end{array}$ & $\begin{array}{l}0.25 \mathrm{MW} \\
0.24 \mathrm{MW}\end{array}$ \\
\hline$V_{i s} \quad$ (p.u.) & \multicolumn{2}{|c|}{1 p.u. } & \multicolumn{2}{|c|}{1.61 p.u. } \\
\hline Note & \multicolumn{4}{|c|}{$\begin{array}{l}V_{\text {islanding }} \text { (after islanding operation) } \\
=\sqrt{\sqrt{(0.5+0.25)^{2}+(0.13+0.24+0.03)^{2}}}\end{array}$} \\
\hline
\end{tabular}

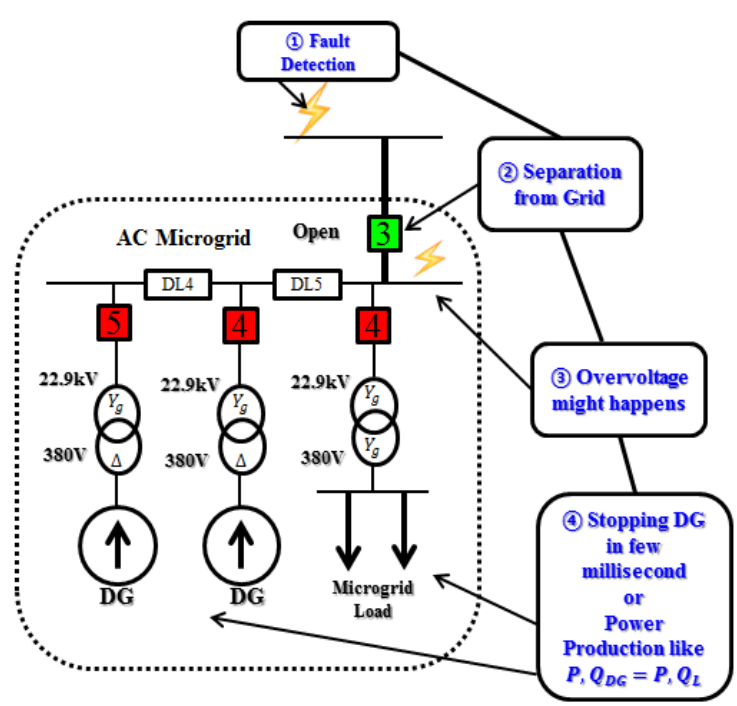

Fig. 13. The scenario of operation of $A C$ microgrid after fault in power system detected

generation is necessary to resolve this problem. For these simulation results, we place emphasis on the contents as below.

1) Overcurrent problem can be dealt with using existing method because there is no difference comparing with conventional power system.

2) Overvoltage problem during islanding operation can be issued based on the power generation and load demand in islanded section.

3) Even though the anti-islanding requirements are strictly applied, overvoltage might happen at the moment of detecting and stopping.

\section{Countermeasures of Overvoltage Problem during Islanding Operation}

Fig. 13 shows the scenario of AC microgrid after fault detection. The most effective countermeasure of overvoltage problem during islanding operation is to halt an 


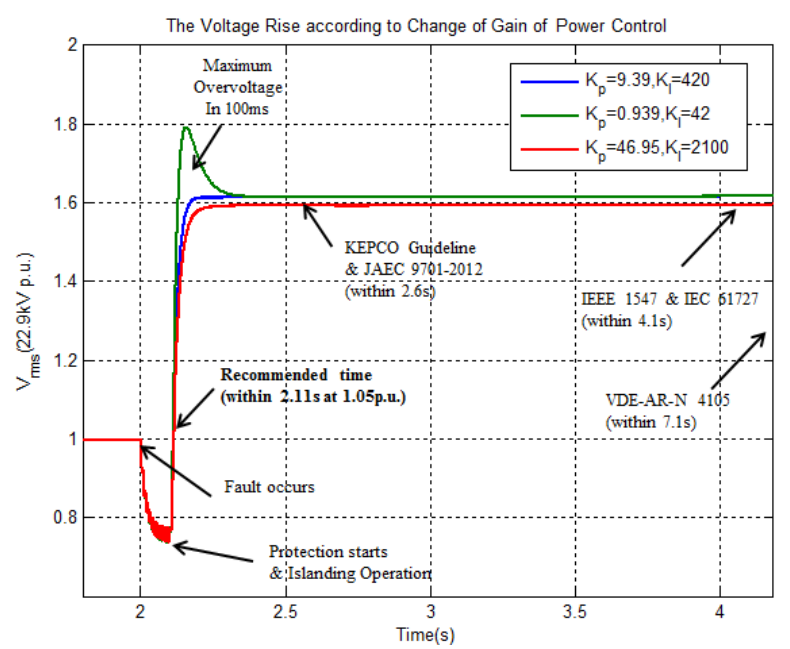

Fig. 14. The scenario of operation of AC microgrid after fault in power system detected (Load : $300 \mathrm{~kW}$, $150 \mathrm{k}$ Var)

operation of DG as soon as possible. However, that should be performed within few milliseconds, at least $10 \mathrm{~ms}$ in this simulation case. Moreover, this required time depends on the comprehensive factors like control gain of grid-feeding converter, load demand at the moment in AC microgrid. In addition, microgrid operator wants a continuous power production in own area EPS even though fault in power system occurs. For reasonable use of AC microgrid, operators should be able to make a decision whether producing or stopping.

\subsection{Fast stop of distributed generation more than conventional anti-islanding requirements}

In grid-feeding control like Fig. 2(b), inner current control makes a PWM voltage signal. It means that the change of transient voltage depend on the response of controller. Fig. 14 shows the voltage rise according to change of outer power control gain. The reference gain of power control is $K_{p}=9.39, K_{i}=420$ respectively. If gains are decreased like green line in Fig. 14, the control approaches to underdamped system. It can be an unexpected overvoltage even though the value of load demand is nearly equal to power generation. In addition, overvoltage problem in AC microgrid is inevitable if other requirements are applied. All DGs must be stopped within $2.11 \mathrm{~s}$ in this simulation condition for prevention of overvoltage. Not only these cases, it is highly necessary to modify other requirements in terms of strict and fast antiislanding based on the power generation and load demand in power systems. However, temporary islanding operation needs for preparation of safe cessation in case of loads susceptible to momentary power failure like server farms or military radars. These susceptible electric loads follow the information technology industry (ITI) curve for operation within no interruption in function region [20]. It

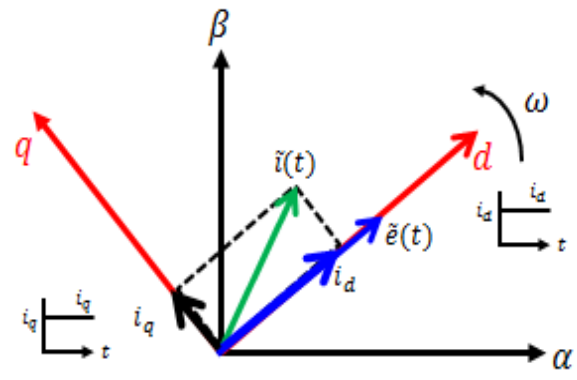

Fig. 15. The d-q frame rotating at synchronous speed

means that we can also consider the case that it is not necessary to halt quickly when islanding operation occurs in case of elimination of factors of overvoltage.

\subsection{Power regulation of distributed generation to load demand}

Overvoltage during islanding operation is determined by difference between power generation and load demand. Hence, overvoltage can be prevented by power regulation of DGs to load demand. Active and reactive power is calculated using d-q components of current and voltage. Fig. 15 shows the stationary $\alpha-\beta$ to rotating $d-q$ frame. Through the theory, it can be transformed to DC quantities and active and reactive power can be written as:

$$
\begin{aligned}
& P=\frac{3}{2}\left(e_{d} i_{d}+e_{q} i_{q}\right) \\
& Q=\frac{3}{2}\left(e_{q} i_{d}-e_{d} i_{q}\right)
\end{aligned}
$$

Assuming that $\mathrm{q}$ axis is aligned on the grid voltage vector, the $\mathrm{d}$ reference $e_{d}=0$, and $P$ and $Q$ can be rewritten as:

$$
\begin{aligned}
& P=\frac{3}{2} e_{q} i_{q} \\
& Q=\frac{3}{2} e_{q} i_{d}
\end{aligned}
$$

When SLG fault or islanding operation occur, load demand $P_{L}$ and $Q_{L}$ are sampled and held. When number of DGs is declared as $n$, then d-q current limit of DGs will be changed as:

$$
i_{\text {d,limit }}=\frac{\frac{2}{3} \times \frac{Q_{L}}{n}}{e_{q}}, \quad i_{q, \text { limit }}=\frac{\frac{2}{3} \times \frac{P_{L}}{n}}{e_{q}}
$$

The concept of adjusting a current limit is that DGs are forcefully controlling their active and reactive power by current limit after the moment of islanding operation. Figs. 16 and 17 shows the active and reactive power of DGs 

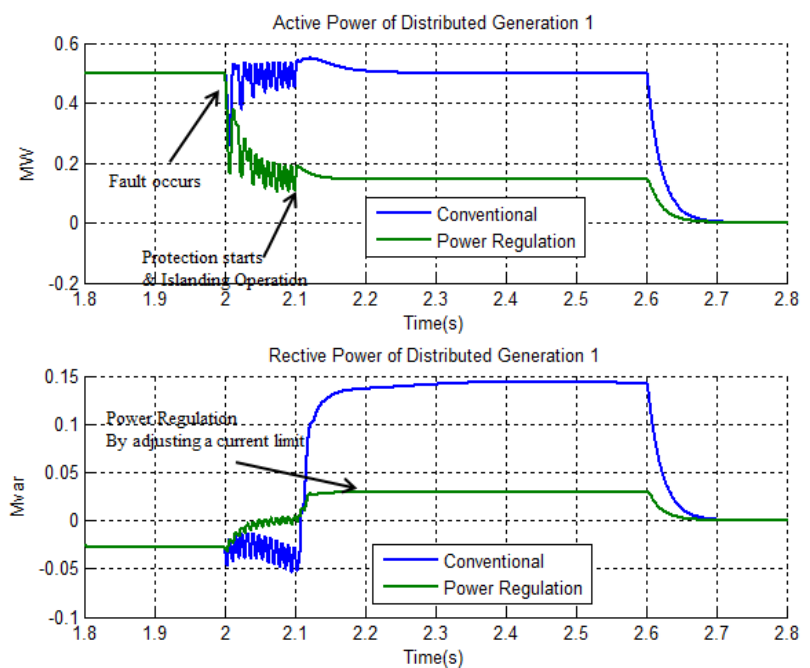

Fig. 16. Active and reactive power of DG 1 (Load : $300 \mathrm{~kW}, 150 \mathrm{kVar})$
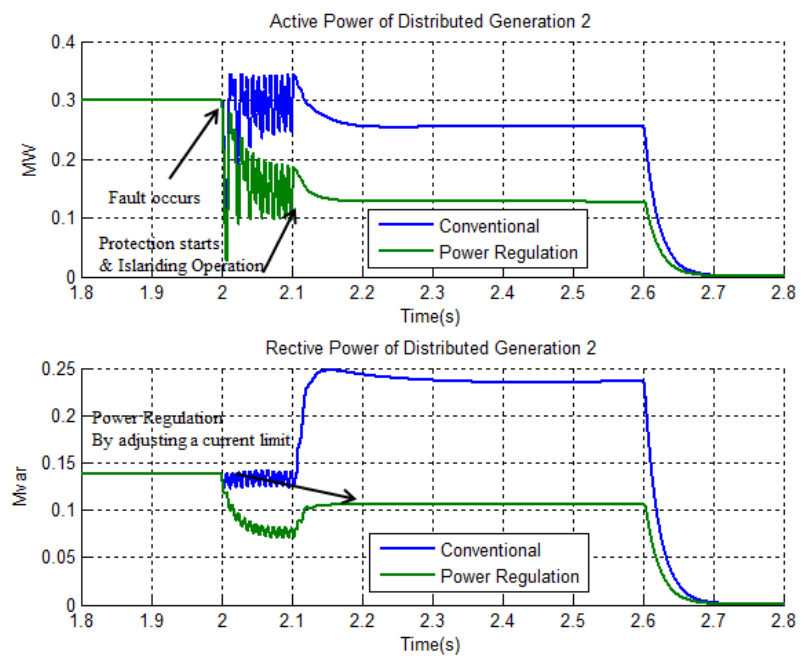

Fig. 17. Active and reactive power of DG 2 (Load : $300 \mathrm{~kW}, 150 \mathrm{kVar})$

Table 5. Simulation results of power regulation (Load : $300 \mathrm{~kW}, 150 \mathrm{kVar})$

\begin{tabular}{c|c|c|c|c}
\hline \multirow{2}{*}{ Index } & \multicolumn{2}{|c|}{$\begin{array}{c}\text { Without power } \\
\text { regulation }\end{array}$} & \multicolumn{2}{c}{$\begin{array}{c}\text { Power } \\
\text { regulation }\end{array}$} \\
\hline \multirow{2}{*}{$P_{D G}, Q_{D G}$} & DG1 & DG2 & DG1 & DG2 \\
\cline { 2 - 5 } & $0.5 \mathrm{MW}$ & $0.25 \mathrm{MW}$ & $0.14 \mathrm{MW}$ & $0.13 \mathrm{MW}$ \\
& $0.13 \mathrm{Mvar}$ & $0.24 \mathrm{MW}$ & $0.03 \mathrm{Mvar}$ & $0.1 \mathrm{Mvar}$ \\
\hline$i_{d}$ & \multicolumn{2}{|c|}{ \pm 2.4} & \multicolumn{2}{|c}{ \pm 0.176} \\
\hline$i_{q}$ & \multicolumn{2}{|c|}{ \pm 2.4} & \multicolumn{2}{|c}{ \pm 0.328} \\
\hline$V_{\text {islanding }}$ (p.u.) & \multicolumn{2}{|c|}{161 p.u. } & \multicolumn{2}{c}{$0.97 \mathrm{p.u}}$. \\
\hline
\end{tabular}

using power regulation in case of load demand $300 \mathrm{~kW}$ and $150 \mathrm{kVar}$. Table 5 summarizes the simulation result of power regulation by autonomous adjusting $\mathrm{d}-\mathrm{q}$ current limit of DG at the moment of islanding operation. For the balance between power generation and load demand,

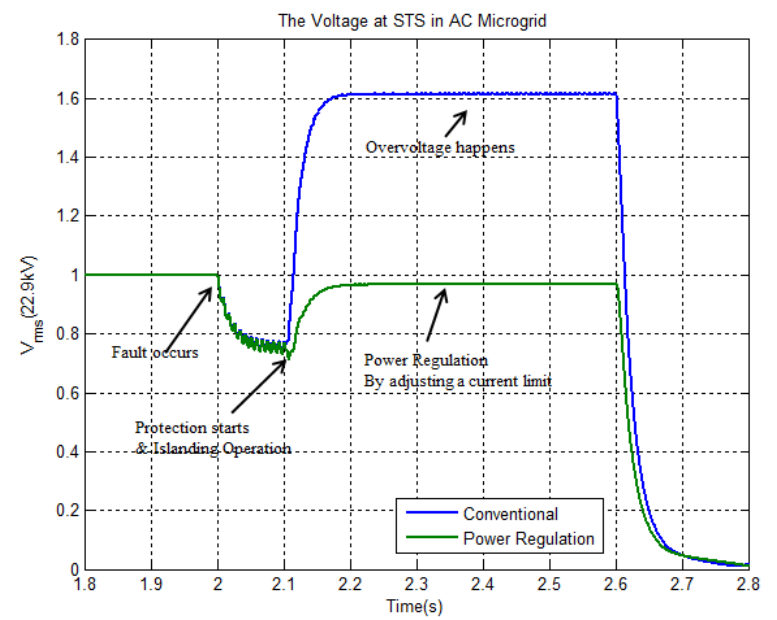

Fig. 18. The RMS voltage at STS of AC microgrid (Load : $300 \mathrm{~kW}, 150 \mathrm{kVar})$

voltage rise can be blocked like Fig. 18. The voltage using power regulation is 0.97 p.u. which is within permissible range. It means that microgrid operators can decide whether to keep or halt. Hence, overvoltage problem can be resolved using both fast stop of DGs and power regulation of DGs.

\section{Conclusion}

The fault analysis of AC microgrid is important for stability of power system. Ever-growing DGs are serious influence on the conventional power system because of inveter-based structures composed of power electronics. Moreover, these control structures of DGs are sensitive when fault occurs. For these reasons, the fault analysis on AC microgrid according to the control structures is carried out in this paper and draws the several conclusions from simulation.

1) Overcurrent issues are identical to existing one because the fault current depends on the bus impedance and prefault voltage regardless of DG.

2) Overvoltage can happen if power generation is much larger than load demand during islanding operation. Also, power system can be damaged in the moment of anti-islanding detection in conventional requirements.

3) Overvoltage during islanding operation can be overcome using fast stop of DG or power regulation of DG as the simulation result in section 5 .

The proposed countermeasures in this paper can prevent overvoltage in AC microgrid during islanding operation. On the other hand, the use of the droop-controlled DES can be another solution of overvoltage problem because it consists of the voltage control and current control [21]. Moreover, droop-controlled DES can switch between grid- 
connected and standalone mode in various cases of operation without change of control structures. By the various operation cases of AC microgrid, a lot of study on the fault cases is required for stable and effective management of area EPS.

\section{Acknowledgements}

This work was supported by "Human Resources Program in Energy Technology" of the Korea Institute of Energy Technology Evaluation and Planning(KETEP), granted financial resources from the Ministry of Trade, Industry \& Energy, Republic of Korea. (No. 20164030201330)

\section{References}

[1] Carlos Moreira, "Microgrids: Operation and Control Under Emergency Conditions", LAP LAMBERT Academic Publishing, 2012

[2] R. Teodorescu et al, "Grid Converters for Photovoltaic and Wind Power Systems", New York: John Wiley \& Sons, 2011

[3] R. Bründlinger and Benoît Bletterie, "Unintentional islanding in distribution grids with a high penetration of inverter-based DG: Probability for islanding and protection methods", Power Tech, 2005 IEEE Russia, Jun. 2005

[4] Joan Rocabert, Alvaro Luna, Frede Blaabjerg and Pedro Rodríguez, "Control of Power Converters in AC Microgrid," IEEE Trans. Power Electronics, vol. 27, no. 11, pp. 4734-4749, Nov. 2012.

[5] David Wenzhong Gao, "Energy Storage for Sustainable Microgrid", Academic Press, 2015

[6] P. Barker, "Overvoltage considerations in applying distributed resources on power systems", 2002 IEEE Power Engineering Society Summer Meeting, 2002, vol. 1, pp. 109-114.

[7] P. Kunder, "Power System Stability and Control", McGraw Hill Inc., 1994.

[8] A. Nelson et al, "Experimental Evaluation of Load Rejection Over-Voltage from Grid-Tied Solar Inverters", Photovoltaic Specialist Conference (PVSC), 2015 IEEE 42nd. Jun. 2015

[9] Farhan Noor et al, "Unintentional Islanding and Comparison of Prevention Techniques", Power Symposium, 2005. Proceedings of the 37th Annual North American, Oct. 2005.

[10] Wei Yee Teoh and Chee Wei Tan, "An Overview of Islanding Detection Methods in Photovoltaic Systems", World Academy of Science, Engineering and Technology International Journal of Electrical, Computer, Energetic, Electronic and Communication Engineering, Vol. 5, No. 10, 2011
[11] IEEE Standards Association, "IEEE 1547 Standard for Interconnecting Distributed Resources with Electric Power Systems," IEEE Standards Association, Piscataway, 2003.

[12] International Electrotechnical Commission, "IEC 61727 ed2.0 Photovoltaic (PV) systems Characteristics of the utility interface," International Electrotechnical Commission, Geneva, 2004.

[13] VDE Association for Electrical, Electronic and Information Technologies, "VDE-AR-N 4105:201108 Power generation systems connected to the lowvoltage distribution network," VDE Association for Electrical, Electronic and Information Technologies, Frankfurt, 2011.

[14] BDEW German Association of Energy and Water Industries, "BDEW Generating Plants Connected to the Medium-Voltage Network," BDEW German Association of Energy and Water Industries, Berlin, 2008.

[15] Japan Electric Association, "Grid Interconnection Code (JEAC 9701-2012)", Japan Electric Association, 2012

[16] Korea Electric Power Corporation, "Guideline of Interconnection Technology of Distributed Generation in Distribution System", Korea Electric Power Corporation, 2015

[17] P. Kunder, "Power System Stability and Control", McGraw Hill Inc., 1994.

[18] Korea Electric Power Corporation, "Technical Standards of KEPCO: Alternating Current Circuit Breaker (ES-5925-0001)", Korea Electric Power Corporation, 2013

[19] Muhammad H. Rashid, "Power Electronics Handbook," Waltham: Academic Press, 2001

[20] Information Technology Industry Council, "ITI (CBEMA) Curve Application Note”, 2000. Available at http://www.itic.org

[21] Josep M. Cuerrero et al, "Hierarchical Control of Droop-Controlled AC and DC Microgrid-A General Approach Toward Standardization", IEEE Trans. Power Electron, vol. 58, no. 1, pp. 916-924, 2011

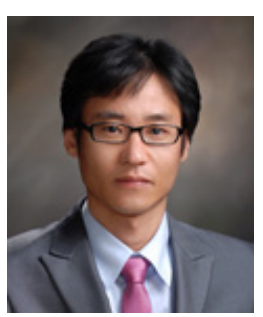

Seong-Su Shin He received the B.S. and M.S. degree in Electric Engineering from Chungbuk National University, Korea, in 2004 and 2007 respectively. $\mathrm{He}$ is currently working toward his $\mathrm{Ph}$. D. in Electrical Engineering at Chungbuk National University. His research interests include operation and design of power distribution systems with distributed generation. 


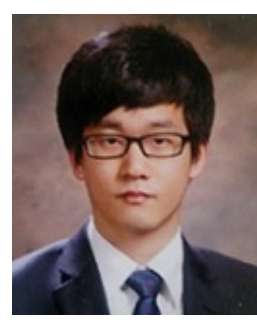

Joon-Seok Oh He received the B.S. and M.S. degree in Electric Engineering from Chungbuk National University, Korea, in 2014 and 2016, respectivley. $\mathrm{He}$ is currently pursuing toward $\mathrm{Ph}$. D. course in Electrical Engineering at Chungbuk National University. His research interests include operation and design of power distribution systems with distributed generation.

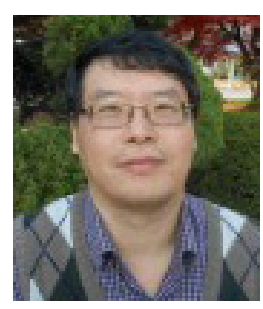

Su-Hyeong Jang He was born in Seoul, KOREA, in 1968. He received his B.S. and M.S. degrees in Electrical Engineering from Hanyang Univ., in 1991 and 1994 , respectively. He is presently pursuing toward his Ph.D. degree at Chungbuk National Univ. Since 1994, He has been with the R\&D Lab., LS Industrial Systems, is currently a principle research engineer. His research interests include protective relay, WAMS based by PMU, Distributed Generation and Electro Magnetic Compatibility of IED.

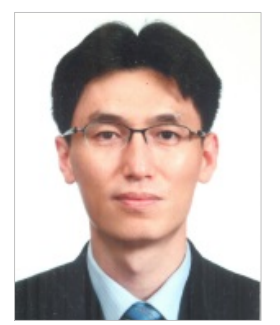

Woo-Kyu Chae He received the B.S. from Sungkyunkwan University and the M.S. degree from Chungbuk National University, Korea, in 2007. He is presently pursuing toward Ph.D. degree at Chungbuk National University. $\mathrm{He}$ is a senior researcher in KEPCO RI(Research Institute of Korea Electric Power Corporation) from 2004. His research activity is focused on the design and control of micro-grid, interconnection of distributed generation. Recently, he is leading the project developing remote microgrid system and its energy management system for small island.

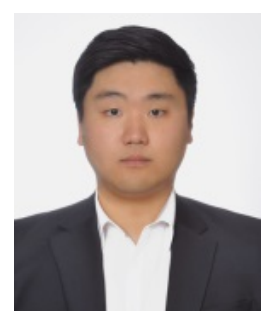

Jong-Ho Park He received the B.S. degree in Electric Engineering from Chungbuk National University, Korea, in 2015. He is currently working toward his M.S. in Electrical Engineering at Chungbuk National University. His research interests include operation and design of power distribution systems with distributed generation.

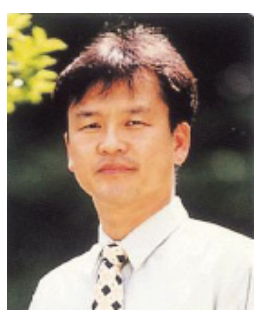

Jae-Eon Kim He received the B.S. and M.S. degrees from the University of Hanyang in 1982 and 1984, respecttively. He was affiliated with KERI as a researcher from 1984 to 1989 ; a senior researcher form 1989 to 1996 ; and a team leader of advanced distribution systems and custom power lab from 1997 to 1998. He received his Ph.D. from Kyoto University, Japan in 1996. He has been a professor at Chungbuk National University since 1998. His current interests are analysis of power quality; operation and design of power distribution systems with distributed generation and advanced distribution systems, such as micro-grid or smart grid. 